ORIGINAL ARTICLE

\title{
Antifungal and antimycotoxigenic potency of Solanum torvum Swartz. leaf extract: isolation and identification of compound active against mycotoxigenic strains of Aspergillus flavus and Fusarium verticillioides
}

\author{
R.U. Abhishek, S. Thippeswamy, K. Manjunath and D.C. Mohana \\ Department of Microbiology and Biotechnology, Bangalore University, Bengaluru, India
}

\section{Keywords}

aflatoxin B1, antifungal, antimycotoxigenic, Aspergillus flavus, fumonisin B1, Fusarium verticillioides, Solanum torvum, torvoside $\mathrm{K}$.

\section{Correspondence}

Devihalli C. Mohana, Department of Microbiology and Biotechnology, Bengaluru University, Jnana Bharathi, Bengaluru-560 056, India.

E-mail: mohanadc@gmail.com

2015/1115: received 3 June 2015, revised 16 July 2015 and accepted 15 September 2015

doi:10.1111/jam.12956

\begin{abstract}
Aims: The main objective of this study was to investigate the antifungal effect of Solanum torvum leaves against different field and storage fungi, and to identify its active compound. In addition, to evaluate in vitro and in vivo inhibitory efficacy on toxigenic strains of Aspergillus flavus and Fusarium verticillioides.

Methods and Results: Leaves of S. torvum were sequentially extracted with petroleum ether, toluene, chloroform, methanol and ethanol. The antifungal compound isolated from chloroform extract was identified as torvoside $\mathrm{K}$ based on spectral analysis. The antifungal activity of chloroform extract and torvoside $\mathrm{K}$ was determined by broth microdilution and poisoned food techniques. The minimum inhibitory concentration (MIC), minimum fungicidal concentration (MFC) and zone of inhibition (ZOI) were recorded. Further, inhibitory effects of chloroform extract and torvoside $\mathrm{K}$ on growth of A. flavus and F. verticillioides, and their toxin productions were evaluated using in vitro and in vivo assays. Torvoside $\mathrm{K}$ showed the significant activity against tested fungi with ZOIs and MICs ranging from 33.4 to $87.4 \%$ and $31.25-$ $250 \mu \mathrm{g} \mathrm{ml}^{-1}$, respectively. Further, torvoside $\mathrm{K}$ showed concentrationdependent antimycotoxigenic activity against aflatoxin B1 and fumonisin B1 production by A. flavus and F. verticillioides, respectively.

Conclusions: It was observed that the compound torvoside $\mathrm{K}$ significantly inhibited the growth of all fungi tested. Growth of A. flavus and F. verticillioides, and aflatoxin B1 and fumonisin B1 productions were completely inhibited in vitro and in vivo by torvoside $\mathrm{K}$ with increasing concentration.

Significance and Impact of the Study: Control of mycotoxigenic fungi requires compounds that able to inhibit both fungal growth and mycotoxin production. The antimycotoxigenic potential of torvoside K of S. torvum is described in this study for the first time. The results indicate the possible use of $S$. torvum as source of antifungal agents against postharvest fungal infestation of food commodities and mycotoxin contaminations.
\end{abstract}

\section{Introduction}

Fungi have been reported to cause damage to grains and other foodstuffs $(>12 \%)$ during pre- and post-harvest processing and storage (Al-Reza et al. 2010). Mycotoxin contamination of various foodstuffs and agricultural commodities is a major problem in the tropics and subtropics, where climatic conditions and agricultural and storage practices are favourable to fungal growth and toxin production (Kumar et al. 2008). Approximately 
25-40\% of foodstuffs worldwide are contaminated with mycotoxins, which are well known to have hazardous effects on human beings and animals (Lutfullah and Hussain 2012). Many species of Aspergillus, Fusarium and Penicillium are not only recognized plant pathogens but are also sources of the important mycotoxins of concern in animal and human health (Placinta et al. 1999). Among the mycotoxins, aflatoxins and fumonisins are the most toxic secondary metabolites mainly produced by species of Aspergillus and Fusarium. Aspergillus flavus and Fusarium verticillioides are two important mycotoxigenic moulds that colonize different kinds of food grains. They spoil various types of foods viz., cereals, legumes, spices, vegetables, fruits etc. and also produce mycotoxins that can be mutagenic, teratogenic, carcinogenic causing feed refusal and emesis in humans or animals (Nguefack et al. 2009; Shukla et al. 2012a). Aflatoxins are highly toxic polyketide secondary metabolites produced mainly by A. flavus. The human health impact of aflatoxin B1 (AFB1) exposure is widespread in developing countries. It is known that AFB1 causes teratogenicity, immunotoxicity, hepatotoxicity and even death in humans and farm animals (Reddy et al. 2010; Rosas-Taraco et al. 2011). Exposure to fumonisins, mainly produced by F. verticillioides, has been associated with several diseases in animals including leucoencephalomalacia in equines, pulmonary oedema in swine, liver cancer in rats and immunosuppression in poultry (Ficoseco et al. 2014). Both aflatoxins and fumonisins are relevant in food and feedstuffs due to their widespread occurrence and cooccurrence (Chulze 2010).

To prevent mycotoxin contamination in grain-based foods and feeds, control of growth of mycotoxigenic moulds is necessary. Management of fungal contamination, biodeterioration and mycotoxin accumulation in foodstuffs is generally achieved using synthetic chemicals (Tripathi et al. 2004; Garcia et al. 2012). However, residues of these chemicals in agricultural produce and by-products cause damage to animal and human health, further, continuous and indiscriminate use of chemical preservatives can lead to the development of resistance in micro-organisms (Al-Reza et al. 2010; Shukla et al. 2012b). Botanicals, being the natural derivatives, are biodegradable and do not leave toxic residues or byproducts to contaminate the environment, hence gaining attention as alternative chemical control measures (Tripathi et al. 2004; Marin et al. 2011). Natural antimicrobials have also shown important antifungal properties, the identification of antifungal compounds from plants is one of the promising and alternative strategy for preventing fungal-deterioration and mycotoxin contaminations (Al-Reza et al. 2010; Marin et al. 2011; Shukla et al. 2012a).
Solanum torvum Swartz. is a small shrub of the Solanaceae family, distributed widely in India, Malaya, China, Phillipines and tropical America. The fruits of S. torvum are edible and traditionally used for the treatment of abscesses, jigger wounds, skin infections and athlete's foot (Balachandran et al. 2012). Pharmacological studies on this plant have demonstrated antiviral (Arthan et al. 2002), immunosecretory (Israf et al. 2004), antioxidant (Sivapriya and Srinivas 2007; Loganayaki et al. 2010; Ramamurthy et al. 2012), analgesic, anti-inflammatory (Ndebia et al. 2007) and anti-ulcerogenic (Nguelefack et al. 2008) activities. Solanum torvum contains a number of potential pharmacologically active chemicals like isoflavonoid sulphate and steroidal glycosides (Yahara et al. 1996; Arthan et al. 2002), chlorogenone and neochlorogenone (Cuervo et al. 1991), triacontane derivatives (Mahmood et al. 1983, 1985), 22- $\beta$-O-spirostanol oligoglycosides (Iida et al. 2005) and 26-O- $\beta$-glucosidase (Arthan et al. 2006). Antimicrobial activity of the leaf and fruit of this plant have been previously reported (Chah et al. 2000; Balachandran et al. 2012; Lalitha et al. 2010). Balachandran et al. (2012) reported the antimicrobial and antimycobacterial activities of methyl caffeate isolated from S. torvum fruit. Although the antimicrobial activity of crude extracts of S. torvum leaves has been reported earlier (Bari et al. 2010; Lalitha et al. 2010), there are no reports on active compound responsible for antifungal activity of $S$. torvum leaves. In this context, an attempt has been made to identify the active compound responsible for antifungal activity as well as its effect on mycotoxin biosynthesis by A. flavus and F. verticillioides.

\section{Materials and methods}

\section{Fungal strains}

Fusarium oxysporum (NCIM 1043) was obtained from the National Chemical Laboratory, Pune (India). Alternaria brassicicola (Sunflower isolate) and Penicillium expansum (Apple isolate) were obtained from the Department of Microbiology, University of Mysore, and Fusarium lateritium (Mulberry isolate) was collected from the Central Sericulture Research and Training Institute, Mysore, India. Maize isolates of Aspergillus flavus (aflatoxigenic strain), Aspergillus fumigatus, Aspergillus ochraceus, Aspergillus tamari, Aspergillus terreus, Fusarium equiseti, Fusarium udum, Fusarium verticillioides (fumonisinogenic strain) and Penicillium citrinum, and sorghum isolates of Alternaria geophila and Curvularia tetramera were used for the study, which were reported in our previous studies (Thippeswamy et al. 2013, 2014). These test fungal strains were maintained on Sabouraud dextrose agar (SDA), and 7 days old cultures were used for further assays. 


\section{Plant material and preparation of plant extracts}

Fresh leaves of S. torvum were collected from the Jnanabharathi Campus, Bangalore University, Bengaluru (India) in the month of July, 2012. The plant sample was authenticated by Prof. Sankara Rao (JCB National Herbarium, Indian Institute of Science, Bengaluru, India) by comparison with the voucher specimens already deposited in the Herbarium. The collected plant material was washed with distilled water and shade-dried at room temperature. The dried leaves were ground well and stored in airtight containers.

Fifty grams of the powdered plant sample was successively extracted in $200 \mathrm{ml}$ solvent with increasing polarity viz., petroleum ether, toluene, chloroform, methanol and ethanol, using a Soxhlet apparatus (Labline, Mumbai, India). All the solvent extracts were concentrated separately under reduced pressure using a rotary flash evaporator (Superfit, Mumbai, India) and stored in airtight glass tubes (Harborne 1998), then checked for antifungal activity.

\section{Bioautographic method}

In preliminary antifungal activity assay, the chloroform extract showed fungal inhibitory activity, which was further subjected to bioautographic method for identification of antifungal band following the procedure of Ficoseco et al. (2014). A spot of active chloroform extract was deposited on thin layer chromatography (TLC) plate (silica gel G60 F254, Merck, Darmstadt, Germany) and eluted using a solvent system of chloroform/methanol $(7 \cdot 5: 2 \cdot 5, \mathrm{v} / \mathrm{v})$, to find the active band of inhibition. TLC plates were prepared in duplicate, one plate was used for bioautography assay and other was kept for comparison. In direct bioautography assay, the plate was overlaid by the SDA (HiMedia, Mumbai, India) and swabbed by the suspension of spores of $F$. verticillioides $\left(10^{5}\right.$ spores $\left.\mathrm{ml}^{-1}\right)$. The plate was incubated at $28 \pm 2{ }^{\circ} \mathrm{C}$ for $48 \mathrm{~h}$ and observation of the inhibition was based on the inhibition caused by the active band. Antifungal band was recorded by comparing with visualized bands on uninoculated TLC plate sprayed with Ehrlich reagent $(2.0 \mathrm{~g}$ of $p$-dimethylaminobenzaldehyde in $50 \mathrm{ml}$ of $95 \%$ ethanol and $50 \mathrm{ml}$ of concentrated hydrochloric acid) and/or $10 \% \quad \mathrm{H}_{2} \mathrm{SO}_{4}$-acetic anhydride-chloroform ( $1: 10: 25, \mathrm{v} / \mathrm{v} / \mathrm{v}$ ) followed by further exposure to $105^{\circ} \mathrm{C}$.

Separation and identification of the antifungal compound from the chloroform extract of Solanum torvum

The TLC band with antifungal activity identified in chloroform extract was separated by column chromatography. The column containing silica gel (mesh size: 60-120;
SRL, Mumbai, India) was eluted with solvents of increasing polarity using a gradient of chloroform and methanol $(10: 0,9: 1 \rightarrow 0: 10, \mathrm{v} / \mathrm{v})$. The eluates were collected in different fractions and concentrated. Based on antifungal activity and TLC analysis, the active fractions of similar profile were pooled together. The active compound was obtained as a white amorphous powder, then analysed for purity of the active compound following TLC analysis and tested with Ehrlich reagent as previously indicated. The isolated compound was subjected to Fourier transform infrared (IR), electrospray ionization-mass spectrometry (ESI-MS), ${ }^{1} \mathrm{H}$ and ${ }^{13} \mathrm{C}$ NMR analyses. In the negative ion mode $[\mathrm{M}+\mathrm{H}]^{-}$of ESI-MS, active compound of $S$. torvum showed a molecular ion peak at $\mathrm{m} / \mathrm{z}$ 740 corresponding to the molecular formula $\mathrm{C}_{39} \mathrm{H}_{64} \mathrm{O}_{13}$ (calculated $m / z$ 740.92). Further, the obtained data were compared with chemical database and published values in literature (Yahara et al. 1996; Iida et al. 2005; Challal et al. 2014).

\section{Screening for antifungal activity against different fungi} by poisoned food technique

Antifungal activity of the chloroform extract (CE) and its active constituent torvoside $\mathrm{K}$ (TK) were tested against 15 different storage and field fungi using poisoned food technique as described by Mohana et al. (2008). CE and TK were dissolved in DMSO and incorporated into SDA to achieve the media of requisite concentration $1000 \mu \mathrm{g} \mathrm{ml}^{-1}$. The control media without test samples was added by the DMSO, the solvent which was used for dissolving the samples. The prepared media were autoclaved, $20 \mathrm{ml}$ of media poured into Petri dishes and allowed to cool. Five millimetre discs of 7 day-old culture of test fungi were placed at the centre of the Petri dishes. The inoculated plates were incubated at $28 \pm 2{ }^{\circ} \mathrm{C}$ for 7 days. Triplicates were maintained for each concentration and control. The fungitoxicity of test samples in terms of percentage of mycelial growth inhibition was calculated as follows:

$$
\text { Growth inhibition }(\%)=(C-T / C) \times 100
$$

where, $C$ is the diameter of mycelial growth in control plates, and $T$ is the diameter of mycelial growth in treated plates.

\section{Determination of minimal inhibitory concentration (MIC) and minimal fungicidal concentration (MFC)}

The MIC and MFC of CE and TK were determined by employing the broth microdilution method following standard procedures (NCCLS 2002; Khaledi et al. 2014). The CE and TK dissolved in 10\% DMSO were first diluted to 
the highest concentration $\left(1000 \mu \mathrm{g} \mathrm{ml}^{-1}\right)$ to be tested, and then serial two-fold dilutions were made in a concentration range from 31.25 to $1000 \mu \mathrm{g} \mathrm{ml}^{-1}$ in 96-well microtitre plate with Sabouraud dextrose broth (SDB). The cell suspension of overnight incubated test fungi in broth culture was adjusted to $10^{4}$ spores $\mathrm{ml}^{-1}$. Each well of 96-well microtitre plate was containing $200 \mu \mathrm{l}$ of two-fold diluted broth of different concentrations and inoculated with $15 \mu \mathrm{l}$ of cell suspension of test fungi. The well containing DMSO without the test samples and inoculated with test fungi was used as the negative control. Synthetic fungicides copper oxychloride 50\% WP (Fungicop-50, Karnatak Agrochemicals Pvt Ltd, Bengaluru, India) and zinc ethylene bisthiocarbamate 75\% WP (Indifil Z-75, Indofil Chemicals Company, Mumbai, India) were used as positive controls in conditions identical to tests samples. The inoculated microtitre plate was sealed with parafilm, then agitated with a microtitre plate shaker (Bio-Rad, Hercules, CA, USA) and incubated at $28 \pm 2^{\circ} \mathrm{C}$ for $72 \mathrm{~h}$. The inoculated plates were observed for the presence or absence of fungal growth. After macroscopic observation, a $10 \mu \mathrm{l}$ of treated broths were radially streaked onto the SDA plates and incubated at $28 \pm 2{ }^{\circ} \mathrm{C}$ for $72 \mathrm{~h}$. After the incubation period, the lowest concentration at which the micro-organism tested did not demonstrate visible growth that value was recorded as MIC. The complete absence of growth on the agar surface in the lowest concentration of the sample tested was defined as MFC. For further confirmation, $50 \mu \mathrm{l}$ of iodo-nitro-tetrazolium chloride (INT, SRL; $200 \mu \mathrm{g} \mathrm{ml}^{-1}$ ) was added to each well and incubated at $30^{\circ} \mathrm{C}$ for $30 \mathrm{~min}$. The pale yellow-coloured INT was reduced to pink colour which indicates the presence of viable microbial cells, while yellow colour remained same where the microbial growth was inhibited (Hajji et al. 2010).

In vitro efficacy of $\mathrm{CE}$ and TK on mycelial growth and mycotoxin production by Aspergillus flavus and Fusarium verticillioides

Inhibitory effects of $\mathrm{CE}$ and TK on growth of mycotoxigenic A. flavus and F. verticillioides, and production of their toxins aflatoxin B1 and fumonisin B1 were evaluated using an in vitro assay. Sucrose-magnesium sulphate-potassium nitrate- yeast extract (SMKY) liquid medium was used to determine the efficacy of $\mathrm{CE}$ and TK against growth of $A$. flavus and $\mathrm{AFB}_{1}$ production (Shukla et al. 2012a; Thippeswamy et al. 2013). SMKY medium $(25 \mathrm{ml})$ was taken in $100 \mathrm{ml}$ flasks, to which requisite amount of test samples were added to get $62 \cdot 5$, $125,250,500$ and $1000 \mu \mathrm{g} \mathrm{ml}^{-1}$ concentrations. The flasks were aseptically inoculated with suspension of toxigenic strain of A. flavus $\left(10^{4}\right.$ spores $\left.\mathrm{ml}^{-1}, 100 \mu \mathrm{l} \mathrm{flask}^{-1}\right)$ and incubated at $28^{\circ} \mathrm{C}$ for 10 days. The flask containing
$0.5 \mathrm{ml}$ of DMSO was maintained as control. The broth cultures were filtered through Whatman no. 1 filter paper, mycelia dried at $100^{\circ} \mathrm{C}$ for $12 \mathrm{~h}$ and mycelial dry weight $(\mathrm{MDW})$ was recorded. The MDW of $\mathrm{CE}$ and TK treated samples were compared with control for their MDW losses. The filtrate was used for the extraction of $\mathrm{AFB}_{1}$ by adding equal volume of chloroform $(25 \mathrm{ml})$ and shaken well in a separating funnel. The chloroform layer was passed through anhydrous sodium sulphate $\left(\mathrm{Na}_{2} \mathrm{SO}_{4}\right)$ and evaporated in dark condition at room temperature. The residue was re-dissolved in $1 \mathrm{ml}$ of chloroform and $10 \mu \mathrm{l}$ of sample was spotted onto the TLC plate adjacent to $\mathrm{AFB}_{1}$ standard (Sigma, Steinheim, Germany). The plate was developed in chloroform-acetone (96:4, v/v), airdried and visualized under ultra-violet light $(365 \mathrm{~nm}$; UV-cabinet, Labline). Qualitative identification of AFB1 content was done by visual comparison of intensity of fluorescence of the samples with standard spots. For quantitative estimation, the fluorescent spots were scrapped off the plates, dissolved in $5 \mathrm{ml}$ cold $\mathrm{CH}_{3} \mathrm{OH}$, and centrifuged at $3000 \mathrm{~g}$ for $5 \mathrm{~min}$. The absorbance of supernatant was measured at $265 \mathrm{~nm}$ using a spectrophotometer (UV1700, Shimadzu, Kyoto, Japan) and the amount of $\mathrm{AFB}_{1}$ content was calculated following formula:

$$
\text { Aflatoxin content }\left(\mu \mathrm{g} \mathrm{kg}^{-1}\right)=[D \times M / E \times L] \times 1000
$$

where, $D$ is absorbance, $M$ is molecular weight of $A_{F B}$ (312), $E$ is molar extinction coefficient of $\mathrm{AFB}_{1}$ (21 800), and $L$ is path length $(1 \mathrm{~cm})$.

The efficacy of $\mathrm{CE}$ and $\mathrm{TK}$ on growth of F. verticillioides and FB1 production was determined in vitro following the method of Bailly et al. (2005) with some modifications. Briefly, $100 \mu \mathrm{l}$ of a spore suspension $\left(10^{4}\right.$ microconidia $\mathrm{ml}^{-1}$ ) of $F$. verticillioides was inoculated into SDB containing the requisite amount of CE and TK $\left(62 \cdot 5,125,250,500\right.$ and $\left.1000 \mu \mathrm{g} \mathrm{ml}^{-1}\right)$, and incubated at $28 \pm 2{ }^{\circ} \mathrm{C}$ for 10 days. Fungal biomass of $F$. verticillioides obtained after the filtration of the SDB medium was measured by weighing the mycelial mat after $48 \mathrm{~h}$ of freezedrying. To estimate FB1 production, mycelial mat of each culture was ground in acetonitrile : water $(1: 1, \mathrm{v} / \mathrm{v})$ and filtered through $0.45 \mu \mathrm{m}$ membrane filter. The filtrate was evaporated on water bath at $60^{\circ} \mathrm{C}$ and the residue was redissolved in $1 \mathrm{ml}$ of methanol. From this, $10 \mu \mathrm{l}$ of sample was spotted adjacent to standard $\mathrm{FB}_{1}$ (Sigma) on TLC plate, then eluted in a solvent system comprising of butanol: acetic acid : water (20:10:10, v/v/v) and allowed to air dry. The air dried TLC plate was sprayed with $0.5 \% \quad p$-anisaldehyde in methanol : acetic acid : $\mathrm{H}_{2} \mathrm{SO}_{4}(85: 10: 0 \cdot 5, \mathrm{v} / \mathrm{v} / \mathrm{v})$ solution followed by heating at $110^{\circ} \mathrm{C}$ for $10 \mathrm{~min}$. After that, the amount of $\mathrm{FB}_{1}$ on TLC plate was estimated qualitatively and quantitatively using spectrophotodensitometer (Bio-Rad, 
Universal Hood II 720BR/02170) at $600 \mathrm{~nm}$ by comparing with different concentrations of standard $\mathrm{FB}_{1}$.

\section{In vivo efficacy of $\mathrm{CE}$ and $\mathrm{TK}$ on growth of mycotoxigenic fungi and, aflatoxin and fumonisin production in viable maize}

Inhibitory effects of $\mathrm{CE}$ and $\mathrm{TK}$ on growth of mycotoxigenic A. flavus and F. verticillioides, and production of their toxins aflatoxin $B_{1}$ and fumonisin $B 1$ were evaluated in vivo using viable maize (Zea mays L.) as model. The efficacy of CE and TK on aflatoxin production in viable maize was determined by following the procedure of Garcia et al. (2012), and Probst and Cotty (2012) with slight modifications. The maize seeds were treated with different concentrations of CE and TK ranging from 62.5 to $1000 \mu \mathrm{g} \mathrm{g}^{-1}$ of maize seeds. The maize seeds without sample treatment were maintained as control. The sample-treated and untreated maize were inoculated with $100 \mu \mathrm{l}$ spore suspension of A. flavus toxigenic strain containing $10^{4}$ spores $\mathrm{ml}^{-1}$. The water activity $\left(a_{\mathrm{w}} 0.95\right)$ of maize was adjusted by aseptically adding sterile distilled water to maize kernels in sterile container as described by Garcia et al. (2012). The inoculated maize were kept for incubation at room temperature for 15 days. After incubation, $5 \mathrm{~g}$ of maize seeds were milled and extracted with $15 \mathrm{ml}$ of acetonitrile-water $(60: 40, \mathrm{v} / \mathrm{v})$ and shaken for $10 \mathrm{~min}$. The extract was filtered through Whatman No. 1 filter paper and the filtrate was extracted with equal volume of chloroform. Further, the extracted AFB1 was estimated qualitatively and quantitatively as described above in vitro assay.

The efficacy of $\mathrm{CE}$ and $\mathrm{TK}$ on $\mathrm{FB} 1$ production in vivo was determined in viable maize seeds following the procedures of Bailly et al. (2005) and Thippeswamy et al. (2014) with minor modifications. Briefly, freshly harvested maize samples were collected and the water activity $\left(a_{w} 0.95\right)$ was adjusted. The maize samples were treated with different concentrations of CE and TK separately $(62.5,125,250$, 500 and $1000 \mu \mathrm{g} \mathrm{ml}^{-1}$ ) and inoculated with $100 \mu \mathrm{l}$ of a spore suspension $\left(10^{4}\right.$ microconidia $\left.\mathrm{ml}^{-1}\right)$ of $F$. verticillioides and incubated at $25^{\circ} \mathrm{C}$ up to 15 days. After incubation, the maize samples were used for FB1 extraction and quantification following the procedure of Bailly et al. (2005). The amount of FB1 was estimated qualitatively and quantitatively using spectrophoto-densitometric method as described above in vitro assay.

\section{Effect of TK on ergosterol content in the plasma} membrane of toxigenic Aspergillus flavus and Fusarium verticillioides

The ergosterol content in the plasma membrane of A. flavus and F. verticillioides was detected by a method described previously by Tian et al. (2012) and Prakash et al. (2014) with slight modifications. Fifty $\mu \mathrm{l}$ spore suspension of toxigenic strains of A. flavus and F. verticillioides containing $10^{6}$ spores $\mathrm{ml}^{-1}$ was inoculated into respective medium (SMKY for A. flavus and SDB for F. verticillioides) containing different concentrations of TK viz., 62.5, 125, 250, 500 and $1000 \mu \mathrm{g} \mathrm{ml}^{-1}$ and incubated at $28 \pm 2^{\circ} \mathrm{C}$ for 4 days. A control set was kept parallel to the treatment sets without treatment. After incubation, mycelia were harvested and washed twice with distilled water. The net wet weights of the cell pellets were recorded. Five millilitre of $25 \%$ alcoholic potassium hydroxide solution $(25 \mathrm{~g} \mathrm{KOH}$ in $35 \mathrm{ml}$ distilled water and made up to $100 \mathrm{ml}$ with absolute ethanol) was added to each sample and vortex mixed for $2 \mathrm{~min}$, followed by incubation at $85 \pm 2^{\circ} \mathrm{C}$ for $4 \mathrm{~h}$ in water bath. Sterols were extracted from each sample by adding a mixture of $2 \mathrm{ml}$ distilled water and $5 \mathrm{ml} n$-heptane. Then, the mixture was sufficiently mixed by vortex for 2 min allowing the layers to separate for $1 \mathrm{~h}$ at room temperature and $n$-heptane layer was analysed by scanning spectrophotometry (UV-1700, Shimadzu) between 230 and $300 \mathrm{~nm}$. Base correction of the absorbance was done with control containing only respective concentration of test compound without inoculation of test fungi. The presence of ergosterol (at $282 \mathrm{~nm}$ ) and the late sterol intermediate 24(28) dehydroergosterol (at 230 and $282 \mathrm{~nm}$ ) in the $n$-heptane layer led to a characteristic curve. The ergosterol amount was calculated as a percentage of the wet weight of the fungal mycelia, was based on the absorbance and wet weight of the initial mycelial pellet. The calculated formula of the ergosterol amount is as follows:

$$
\begin{aligned}
& \text { \%ergosterol }+\% 24(28) \text { dehydroergosterol } \\
& =(A 282 / 290) / \text { pellet weight },
\end{aligned}
$$

$\% 24(28)$ dehydroergosterol $=(A 230 / 518) /$ pellet weight,

\%ergosterol $=(\%$ ergosterol $+\% 24(28)$ dehydroergosterol $)$ - \%24(28) dehydroergosterol

where, 290 and 518 are the $E$ values (in percentages per $\mathrm{cm}$ ) determined for crystalline ergosterol and 24(28) dehydroergosterol, respectively, and pellet weight is the net wet weight $(\mathrm{g})$.

\section{Statistical analysis}

The experiments were performed in triplicate and values were expressed as means \pm standard error. Analysis of variance was conducted, and the differences between 
values were tested for significance by ANOVA with the SPSS 19 (IBM, Armonk, NY, USA) programme. Differences at $P \leq 0.05$ were considered statistically significant.

\section{Results}

\section{Antifungal activity visualized by bioautographic assay}

The chloroform extract of S. torvum leaves showed the highest antifungal activity than other extracts viz., petroleum ether, toluene, methanol and ethanol extracts. A TLC approach was followed to identify the active compound responsible for the observed antifungal activity in chloroform extract of S. torvum. Bioautographic and TLC analysis indicated that the band with $\mathrm{Rf}=0.56$ showed the observed antifungal activity. The active band was visualized in TLC plate after spraying with Ehrlich reagent and/or $10 \% \mathrm{H}_{2} \mathrm{SO}_{4}$-acetic anhydride-chloroform, separately. The brick-red colour confirmed that the compound belongs to glycoside group.

\section{Identification of the active compound isolated from the} chloroform extract of Solanum torvum

The chloroform extract was subjected to column chromatography with a gradient elution of chloroform and methanol $(10: 0,9: 1 \rightarrow 0: 10, \mathrm{v} / \mathrm{v})$ to afford 26 fractions. The 9th and 10th fractions of column chromatography showed similar chromatographic profile and bioautographic results (Fig. 1), which were pooled together. The fraction was further purified by preparative TLC, then the compound obtained as amorphous powder and subjected to spectral analysis. The compound was characterized as torvoside $\mathrm{K}$ based on the comparison of its spectral data with the reported values in literature, which was previously reported as torvoside $\mathrm{C}$ by Yahara et al. (1996). In the ESI-MS spectrum, the isolated compound showed a molecular ion peak $\left([\mathrm{M}+\mathrm{H}]^{-}\right)$at $m / z$ $740\left(\mathrm{C}_{39} \mathrm{H}_{64} \mathrm{O}_{13}\right.$, requires, 740.92) corresponding to the molecular formula $\mathrm{C}_{39} \mathrm{H}_{64} \mathrm{O}_{13}$. The ${ }^{13} \mathrm{C}$-NMR spectrum showed 39 carbon signals and ${ }^{1} \mathrm{H}-\mathrm{HMR}$ spectrum showed 64 proton signals similar to those of reported values (Yahara et al. 1996; Iida et al. 2005; Challal et al. 2014). In an earlier report, it was reported as glycoside of neosolaspigenin having $22-\alpha-O$-spirostane skeleton because its ${ }^{13} \mathrm{C}$-NMR signals due to the aglycone moiety were identical with those of neosolaspigenin (Yahara et al. 1996). However, the ${ }^{13} \mathrm{C}$-NMR signals of torvoside $\mathrm{K}$ were coincident with those of the sapogenol moiety of this torvoside K (Iida et al. 2005; Challal et al. 2014). Therefore, torvoside $\mathrm{K}$ was determined to be $6-O-\alpha-\mathrm{L}$-rhamnopyranosyl-( $1 \rightarrow 3)-\beta$-D-quinovopyranosyl $\quad(22 R, 23 S, 25 R)-3 \beta, 6$ $\alpha, 23$-trihydroxy- $5 \alpha$-spirostane (Fig. 2).

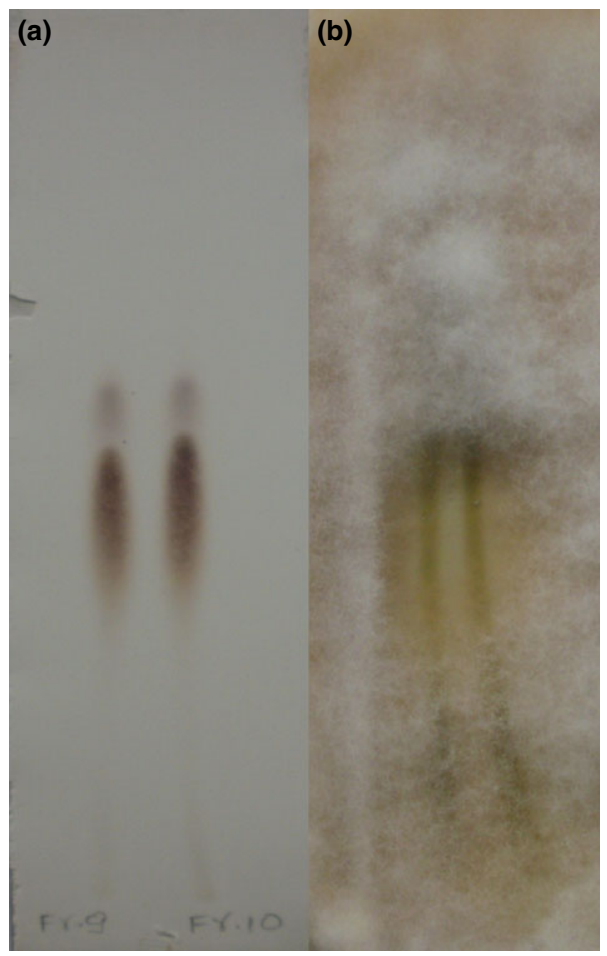

Figure 1 Silica gel chromatograms of 9th and 10th fractions obtained from column chromatography of chloroform extract of Solanum torvum leaves. The plates were developed in chloroform : methanol $(7 \cdot 5: 2 \cdot 5, \mathrm{v} / \mathrm{v})$. Chromatograms were (a) observed after spraying with $10 \% \quad \mathrm{H}_{2} \mathrm{SO}_{4}$ : acetic anhydride : chloroform (1: $10: 25, v / v / v)$ and further exposure to $105^{\circ} \mathrm{C}$ (b) bioautographed against Fusarium verticillioides.

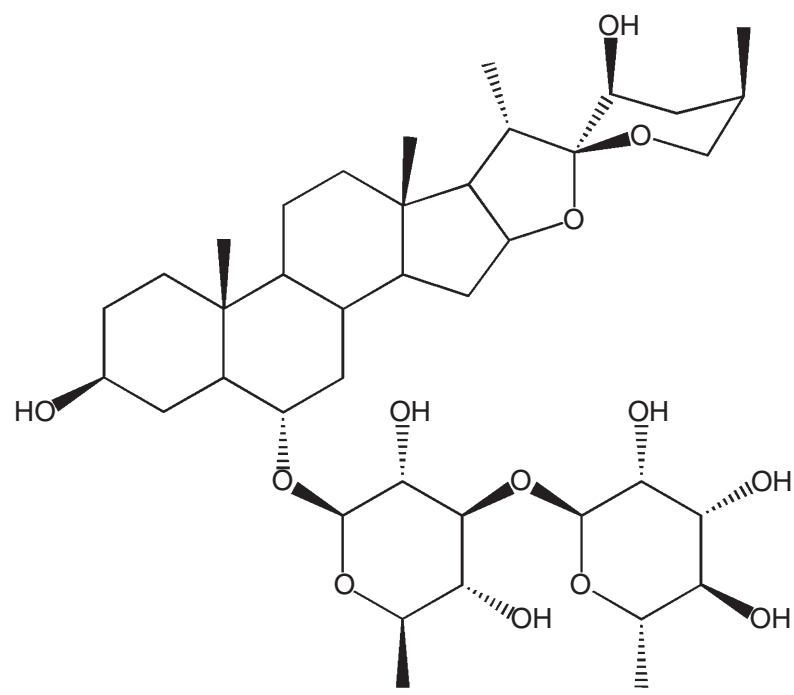

Figure 2 Structure of torvoside $\mathrm{K}$ isolated from Solanum torvum leaves. 
Antifungal efficacy of CE and TK assessed using poisoned food technique and microdilution method

The growth inhibitory effects of CE and TK were screened against a panel of 15 fungal pathogens containing storage and field fungi are given in Table 1. The percentage of growth inhibition by the CE and TK was estimated by measuring the growth diameter of colony grown in the medium with treatment and control. Most of the treated field fungi were susceptible at $1000 \mu \mathrm{g} \mathrm{ml}^{-1}$ concentration of CE and TK with inhibition of spore germination. Among the fungi tested, $P$. expansum, A. flavus and A. tamari were found to be most resistant, with the mycelial growth inhibition 26.5, 28.0 and $30.0 \%$, respectively. The field fungi such as A. brassicicola (87.4\%), F. verticillioides (84.2\%), F. udum $(84 \cdot 1 \%)$ and C. tetramera $(82 \cdot 4 \%)$, were found be most susceptible organisms at $1000 \mu \mathrm{g} \mathrm{ml}{ }^{-1}$. At the concentration of $1000 \mu \mathrm{g} \mathrm{ml}^{-1}$, TK caused more than $50 \%$ mycelial inhibition of most of the fungi except P. expansum, A. flavus and A. tamari. However, remarkable antifungal index $(50 \cdot 2-87 \cdot 4 \%)$ was recorded by TK against rest of the fungi at the same concentration. Among the two mycotoxigenic fungi tested, aflatoxigenic strain of A. flavus was found to be resistant, whereas fumonisinogenic strain of $F$. verticillioides was susceptible to $\mathrm{TK}$ and $\mathrm{CE}$.
In broth microdilution assay, the TK showed significant inhibitory activity against most of the pathogenic fungi tested with lower MIC and MFC than that of CE and copper oxychloride 50\%. The results revealed that the antifungal activity of TK was comparable to zinc ethylene bisthiocarbamate $75 \%$ which showed the significant inhibitory activity against a wide range of fungi tested. The test samples showed significant inhibitory activity against field fungi tested viz., Alternaria spp., Curvularia sp. and Fusarium spp., with lower MIC/MFC values than those recorded for storage fungi viz., Aspergillus spp. and Penicillium spp. On comparative evaluation with synthetic fungicides copper oxychloride $50 \%$ and zinc ethylene bisthiocarbamate 75\%, CE and TK showed varying degrees of MIC and MFC values against different fungi tested. Among the samples tested, copper oxychloride $50 \%$ was found least effective against any of the fungi tested, most of the fungi were not completely inhibited even at concentration of $1000 \mu \mathrm{g} \mathrm{ml}-1$.

\section{Inhibitory effect $\mathrm{CE}$ and TK on fungal growth and mycotoxin production in culture medium}

Inhibitory effects of $\mathrm{CE}$ and TK on mycelial growth, and production of aflatoxin B1 by A. flavus and fumonisin B1 by $F$. verticillioides were evaluated using suitable growth media. The biomass (MDW) of A. flavus and

Table 1 Antifungal activity of chloroform extract of Solanum torvum, torvoside $\mathrm{K}$ and synthetic fungicides against different field and storage fungi

\begin{tabular}{|c|c|c|c|c|c|c|c|c|c|c|}
\hline \multirow[b]{2}{*}{ Test fungi } & \multicolumn{3}{|c|}{ Chloroform extract } & \multicolumn{3}{|l|}{ Torvoside $\mathrm{K}$} & \multicolumn{2}{|l|}{$\mathrm{CO}$} & \multicolumn{2}{|l|}{ ZEB } \\
\hline & $\begin{array}{l}\% \text { Mycelial } \\
\text { inhibition* }\end{array}$ & MIC & MFC & $\begin{array}{l}\text { \% Mycelial } \\
\text { inhibition* }\end{array}$ & MIC & MFC & MIC & MFC & MIC & MFC \\
\hline Alternaria brassicicola & $79.34 \pm 0.32$ & 125 & 250 & $87.4 \pm 0.32$ & $31 \cdot 25$ & 125 & $31 \cdot 25$ & 500 & $31 \cdot 25$ & 62.5 \\
\hline Alternaria geophila & $60.40 \pm 0.26$ & 125 & 250 & $76.0 \pm 0.26$ & $62 \cdot 5$ & 125 & 125 & $>1000$ & 31.25 & 500 \\
\hline Aspergillus flavus† & $28.00 \pm 0.14$ & 250 & $>1000$ & $33.4 \pm 0.14$ & 125 & 500 & 250 & $>1000$ & 125 & 1000 \\
\hline Aspergillus fumigatus & $42.78 \pm 0.76$ & 250 & 1000 & $50.2 \pm 0.76$ & 125 & 250 & 250 & $>1000$ & 250 & 1000 \\
\hline Aspergillus ochraceus & $49.50 \pm 0.08$ & 125 & 500 & $56 \cdot 8 \pm 0.08$ & 125 & 250 & 250 & 500 & $62 \cdot 5$ & 500 \\
\hline Aspergillus tamari & $30.00 \pm 0.12$ & 500 & $>1000$ & $34 \cdot 3 \pm 0.12$ & 250 & 1000 & 500 & $>1000$ & 125 & 250 \\
\hline Aspergillus terreus & $41.05 \pm 0.45$ & 125 & 500 & $52 \cdot 0 \pm 0.45$ & $62 \cdot 5$ & 250 & 250 & $>1000$ & 125 & 250 \\
\hline Curvularia tetramera & $69.32 \pm 0.76$ & $62 \cdot 5$ & 250 & $82.4 \pm 0.76$ & 31.25 & 125 & 250 & $>1000$ & $31 \cdot 25$ & 500 \\
\hline Fusarium equiseti & $52.90 \pm 0.33$ & 125 & 250 & $63.5 \pm 0.33$ & $62 \cdot 5$ & 125 & 250 & $>1000$ & 31.25 & 125 \\
\hline Fusarium lateritium & $67.78 \pm 0.14$ & 125 & 250 & $79.8 \pm 0.14$ & 62.5 & 250 & 500 & $>1000$ & 31.25 & 125 \\
\hline Fusarium oxysporum & $68.00 \pm 0.43$ & 125 & 250 & $79.5 \pm 0.43$ & $62 \cdot 5$ & 125 & 500 & $>1000$ & 31.25 & 125 \\
\hline Fusarium udum & $73.56 \pm 0.22$ & $62 \cdot 5$ & 125 & $84.1 \pm 0.22$ & $31 \cdot 25$ & $62 \cdot 5$ & 250 & $>1000$ & $31 \cdot 25$ & 125 \\
\hline Fusarium verticillioides & $76.42 \pm 0.27$ & 125 & 250 & $84.2 \pm 0.27$ & 62.5 & 250 & 1000 & $>1000$ & $62 \cdot 5$ & 125 \\
\hline Penicillium expansum & $26.25 \pm 0.11$ & 500 & $>1000$ & $29.5 \pm 0.11$ & 250 & $>1000$ & 500 & $>1000$ & 500 & $>1000$ \\
\hline Penicillium citrinum & $30.44 \pm 0.00$ & 500 & $>1000$ & $33.6 \pm 0.00$ & 250 & $>1000$ & 1000 & $>1000$ & 500 & $>1000$ \\
\hline
\end{tabular}

CO: Copper oxychloride 50\%; ZEB: Zinc ethylene bisthiocarbamate $75 \%$.

Minimum inhibitory concentration (MIC) and minimum fungicidal concentration (MFC) values are expressed in $\mu \mathrm{g} \mathrm{ml}^{-1}$.

Data given are the mean values of three replicates \pm standard error $(P \leq 0.05)$.

*Per cent mycelial inhibition at sample concentration of $1000 \mu \mathrm{g} \mathrm{ml}^{-1}$.

$\uparrow$ Aflatoxin B1 producing strain.

\$Fumonisin B1 producing strain. 
Table 2 In vitro efficacy of chloroform extract of Solanum torvum and torvoside K on mycelial dry weight (MDW), FB1 production from Aspergillus flavus and FB1 production from Fusarium verticillioides

\begin{tabular}{|c|c|c|c|c|c|c|c|c|}
\hline \multirow[b]{3}{*}{$\begin{array}{l}\text { Concentration* } \\
\left(\mu \mathrm{g} \mathrm{ml}^{-1}\right)\end{array}$} & \multicolumn{4}{|c|}{$\begin{array}{l}\text { Effect on growth of } A \text {. flavus and AFB1 production in SMKY } \\
\text { medium }\end{array}$} & \multicolumn{4}{|c|}{$\begin{array}{l}\text { Effect on growth of } F \text {. verticillioides and FB1 production in } \\
\text { SDB medium }\end{array}$} \\
\hline & \multicolumn{2}{|c|}{ Chloroform extract } & \multicolumn{2}{|l|}{ Torvoside $\mathrm{K}$} & \multicolumn{2}{|c|}{ Chloroform extract } & \multicolumn{2}{|l|}{ Torvoside $\mathrm{K}$} \\
\hline & MDW (mg) & $\begin{array}{l}\text { AFB1 content } \\
\left(\mu \mathrm{g} \mathrm{I}^{-1}\right)\end{array}$ & MDW (mg) & $\begin{array}{l}\text { AFB1 content } \\
\left(\mu \mathrm{g} \mathrm{I}^{-1}\right)\end{array}$ & MDW (mg) & 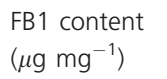 & MDW (mg) & $\begin{array}{l}\text { FB1 content } \\
\left(\mu \mathrm{g} \mathrm{mg}^{-1}\right)\end{array}$ \\
\hline Control & $548.0 \pm 9.3$ & $1478.4 \pm 28.7$ & $548 \cdot 0 \pm 9 \cdot 3$ & $1478.4 \pm 28.7$ & $140.8 \pm 8.7$ & $4.50 \pm 0.04$ & $140.8 \pm 8.7$ & $4.50 \pm 0.04$ \\
\hline $62 \cdot 5$ & $473.0 \pm 9.6$ & $1331.0 \pm 25.5$ & $423 \cdot 0 \pm 10 \cdot 2$ & $1108.0 \pm 28.9$ & $112.0 \pm 8.8$ & $4.30 \pm 0.02$ & $94.0 \pm 8.1$ & $2.80 \pm 0.03$ \\
\hline 125 & $394.3 \pm 8.9$ & $944.6 \pm 28.6$ & $174.6 \pm 5 \cdot 3$ & $102.6 \pm 21.5$ & $98 \cdot 4 \pm 7 \cdot 3$ & $2.24 \pm 0.03$ & $73 \cdot 0 \pm 6 \cdot 5$ & $0.85 \pm 0.02$ \\
\hline 250 & $292 \cdot 3 \pm 6 \cdot 5$ & $517 \cdot 8 \pm 25 \cdot 4$ & $78.9 \pm 3.8$ & ND & $54 \cdot 3 \pm 5 \cdot 2$ & $0.98 \pm 0.01$ & $32 \cdot 3 \pm 6 \cdot 4$ & ND \\
\hline 500 & $135 \cdot 6 \pm 3 \cdot 2$ & $95 \cdot 71 \pm 21.4$ & ND & ND & $37.0 \pm 4.5$ & ND & ND & ND \\
\hline 1000 & $37.0 \pm 2.7$ & ND & ND & ND & ND & ND & ND & ND \\
\hline
\end{tabular}

Data given are the mean of three replicates \pm standard error $(P \leq 0.05)$.

ND, not detected; SMKY, Sucrose-magnesium sulphate-potassium nitrate- yeast extract; SDB, Sabouraud dextrose broth.

${ }^{*}$ In vitro treatment with different concentrations of samples in $\mu \mathrm{g} \mathrm{ml}^{-1}$ of growth medium.

F. verticillioides and mycotoxin production were significantly inhibited by CE and TK in a dose-dependent manner (Table 2). The amount of $\mathrm{AFB}_{1}$ production in control was found to be $1478.4 \pm 28 \cdot 7 \mu \mathrm{g} \mathrm{l}^{-1}$ and $\mathrm{FB}_{1}$ was $4.50 \pm 0.04 \mu \mathrm{g} \mathrm{mg}^{-1}$ of fungal biomass. $\mathrm{AFB}_{1}$ and $\mathrm{FB}_{1}$ productions were completely inhibited by $\mathrm{TK}$ at concentrations higher than $250 \mu \mathrm{g} \mathrm{ml}^{-1}$, while fungal biomass were completely inhibited at concentrations higher than $500 \mu \mathrm{g} \mathrm{ml}^{-1}$. Similarly, in the case of $\mathrm{CE}, \mathrm{AFB}_{1}$ production was inhibited at $1000 \mu \mathrm{g} \mathrm{ml}^{-1}$ with no complete inhibition of fungal biomass, whereas $\mathrm{FB}_{1}$ production was inhibited at concentrations higher than $500 \mu \mathrm{g} \mathrm{ml}^{-1}$ with complete inhibition of fungal biomass at $1000 \mu \mathrm{g} \mathrm{ml}^{-1}$.

\section{Inhibitory effect of CE and TK on aflatoxin and fumonisin production in viable maize}

In vivo inhibitory efficacy of $\mathrm{CE}$ and $\mathrm{TK}$ on production of aflatoxin B1 by A. flavus and fumonisin B1 by F. verticillioides were evaluated using viable maize as model
(Table 3). The amount of AFB1 and FB1 production in control were found to be $1294 \cdot 0 \pm 20 \cdot 1 \mu \mathrm{g} \mathrm{kg}^{-1}$ and $2.65 \pm 0.03 \mu \mathrm{g} \mathrm{g}^{-1}$, respectively. AFB1 production in maize was inhibited completely by TK at $1000 \mu \mathrm{g} \mathrm{kg}^{-1}$, but CE did not inhibit AFB1 production completely. Similarly, FB1 production was inhibited by TK at concentrations higher than $500 \mu \mathrm{g} \mathrm{kg}^{-1}$, whereas CE inhibited at $1000 \mu \mathrm{g} \mathrm{kg}^{-1}$.

\section{Effectiveness of active compound TK on ergosterol content in the plasma membrane of toxigenic fungi}

The inhibitory effects of TK on ergosterol content in the plasma membrane of A. flavus and F. verticillioides are shown in Fig. 3. When compared to control, the reduction percentage of ergosterol content in the plasma membrane of A. flavus by TK was recorded to be $48 \cdot 67 \%$, $57 \cdot 30 \%, 70 \cdot 43 \%$ at $62 \cdot 5,125$, and $250 \mu \mathrm{g} \mathrm{ml}^{-1}$, respectively (data not presented). Similarly, in F. verticillioides, a reduction percentage of the ergosterol content as com-
Table 3 In vivo efficacy of chloroform extract of Solanum torvum and torvoside $\mathrm{K}$ on AFB1 production from Aspergillus flavus and FB1 production from Fusarium verticillioides in maize

\begin{tabular}{llllll}
\hline & \multicolumn{2}{l}{$\begin{array}{l}\text { AFB1 production }\left(\mu \mathrm{gg}^{-1}\right) \text { in } \\
\text { maize }\end{array}$} & & \multicolumn{2}{l}{$\begin{array}{l}\text { FB1 production }\left(\mu \mathrm{g} \mathrm{g}^{-1}\right) \text { in } \\
\text { maize }\end{array}$} \\
\cline { 2 - 3 } $\begin{array}{l}\text { Concentration* } \\
\left(\mu \mathrm{g} \mathrm{g}^{-1}\right)\end{array}$ & $\begin{array}{l}\text { Chloroform } \\
\text { extract }\end{array}$ & Torvoside K & & $\begin{array}{l}\text { Chloroform } \\
\text { extract }\end{array}$ & Torvoside K \\
\hline Control & $1294.0 \pm 20.1$ & $1294.0 \pm 20.1$ & $2.65 \pm 0.03$ & $2.65 \pm 0.03$ \\
125 & $1191.0 \pm 18.5$ & $1008.5 \pm 19.4$ & & $2.20 \pm 0.04$ & $1.56 \pm 0.03$ \\
250 & $1014.6 \pm 19.1$ & $716.8 \pm 17.5$ & $1.24 \pm 0.02$ & $0.19 \pm 0.02$ \\
500 & $677.8 \pm 15.4$ & $241.3 \pm 12.1$ & $0.39 \pm 0.01$ & ND \\
1000 & $163.4 \pm 13.3$ & ND & ND & ND \\
\hline
\end{tabular}

Data given are the mean of three replicates \pm standard error $(P \leq 0.05)$.

ND, not detected.

*In vivo treatment with different concentrations of samples in $\mu \mathrm{g} \mathrm{g}^{-1}$ of viable maize. 
(a)

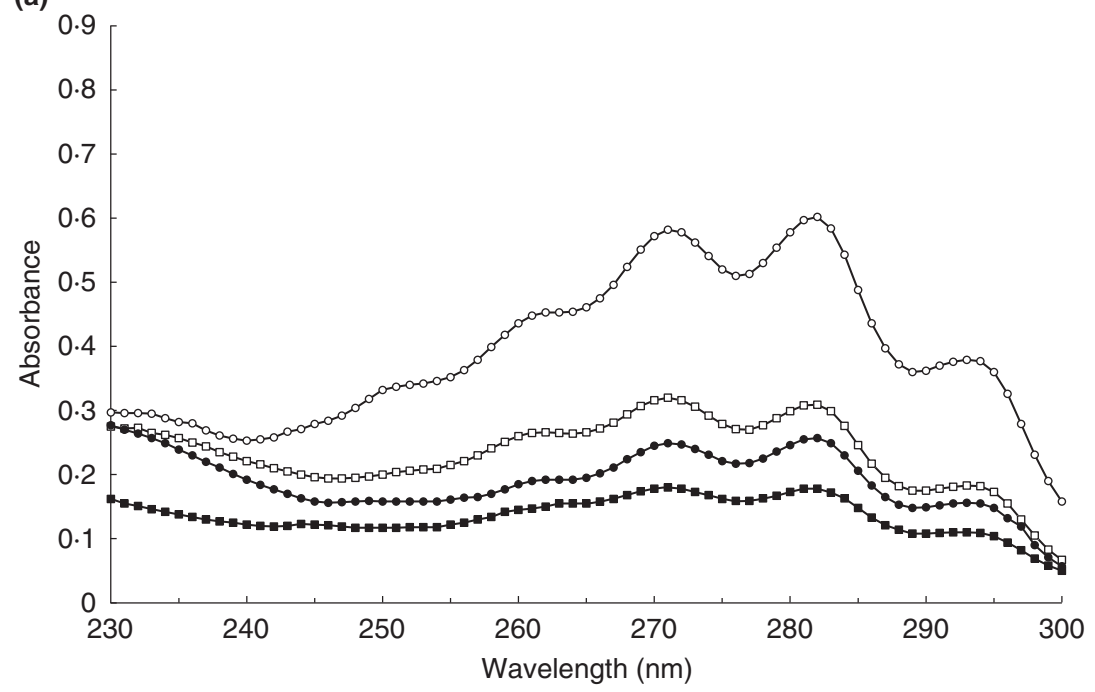

(b)

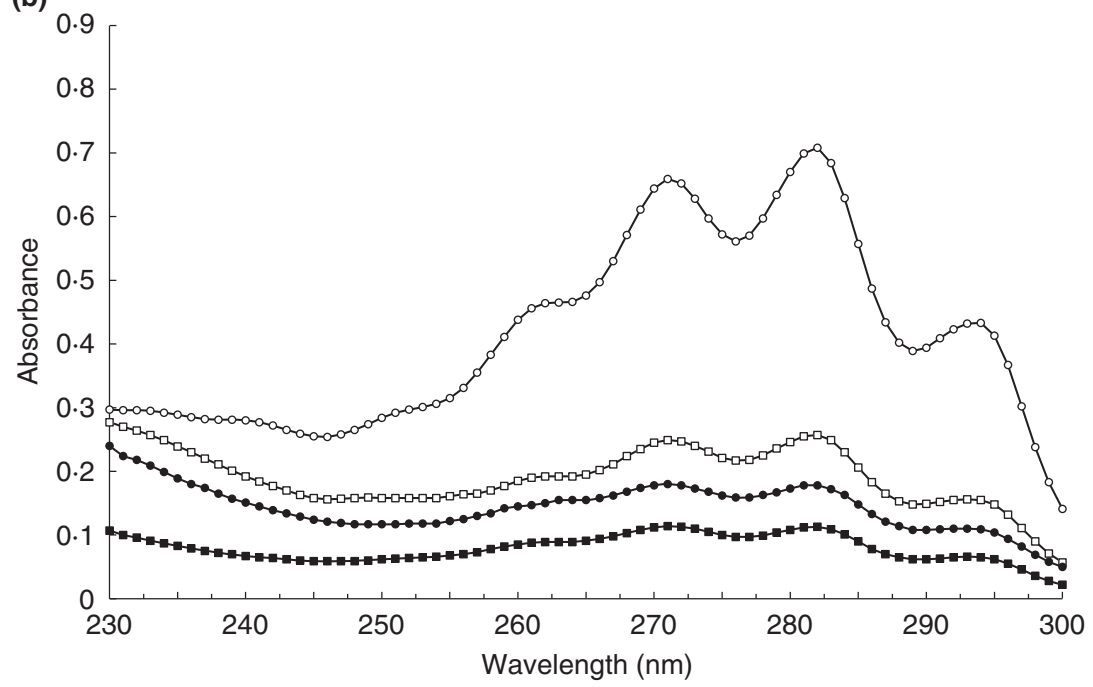

Figure 3 Effect of different concentrations of torvoside $\mathrm{K}$ on ergosterol content in the plasma membrane of toxigenic strains of (a) Aspergillus flavus and (b) Fusarium verticillioides. (O) Control; ( $\square) 62.5 \mu \mathrm{g} \mathrm{ml}^{-1}$; (•) $125 \mu \mathrm{g} \mathrm{ml}^{-1}$ and (ロ) $250 \mu \mathrm{g} \mathrm{ml}^{-1}$. pared with the control was observed at $63.70 \%$ for $62.5 \mu \mathrm{g} \mathrm{ml}^{-1}, \quad 74.85 \%$ for $125 \mu \mathrm{g} \mathrm{ml}^{-1}, 84.03 \%$ for $250 \mu \mathrm{g} \mathrm{ml}^{-1}$. A dose-dependent decrease in ergosterol production in both A. flavus and F. verticillioides was observed when isolates were grown in the presence of TK. At 500 and $1000 \mu \mathrm{g} \mathrm{ml}^{-1}$ concentrations of $\mathrm{TK}$, $100 \%$ reduction in ergosterol content was observed in both A. flavus and F. verticillioides. The results demonstrated that the ergosterol content (at $282 \mathrm{~nm}$ ) in the plasma membrane of both A. flavus and F. verticillioides was completely inhibited at concentrations higher than $500 \mu \mathrm{g} \mathrm{ml}^{-1}$.

\section{Discussion}

In this study, we evaluated the antifungal and antimycotoxigenic capability of torvoside $\mathrm{K}$ isolated from
S. torvum Swartz. leaf extract on growth of A. flavus and F. verticillioides, and mycotoxin production in viable maize grain at adjusted $a_{\mathrm{w}}$ and inoculum level. Conditions studied in vivo were close to conditions that may occur during pre- and post-harvest of cereals. Further, we also investigated the antifungal potency against a panel of 15 different field and storage fungi using in vitro assays. The antifungal and antimycotoxigenic properties of torvoside $\mathrm{K}$ isolated from S. torvum leaves have been reported here for the first time.

The chloroform extract of $S$. torvum yielded two active fractions- 9th and 10th of column chromatography, which were pooled together due to similar chromatographic profile and bioautographic results. The bioautographic assay showed that only one band inhibited fungal growth in each of these fractions. TLC chromatogram sprayed with $10 \% \mathrm{H}_{2} \mathrm{SO}_{4}$ : acetic anhydride: chloroform 
( $1: 10: 25, \mathrm{v} / \mathrm{v} / \mathrm{v})$ showed two brick-red coloured bands, among which the first band $\left(R_{\mathrm{f}} 0 \cdot 56\right)$ showed antifungal activity. The active band was separated as white amorphous powder, which was identified as torvoside $\mathrm{K}$ based on spectral analysis. In an earlier report by Yahara et al. (1996), torvoside C has been reported from aerial parts of $S$. torvum, a glycoside of neosolaspigenin having 22$\alpha$-O-spirostane skeleton because its ${ }^{13} \mathrm{C}$-NMR signals due to the aglycone moiety were identical with those of neosolaspigenin. Later, Iida et al. (2005) have reported the same compound from the fruits of S. torvum, the compound was determined to be torvoside $\mathrm{K}$ as the ${ }^{13} \mathrm{C}-\mathrm{NMR}$ signals were coincident with those of the sapogenol moiety of this torvoside K. Further, Challal et al. (2014) reported torvoside $\mathrm{K}$ from aerial parts of S. torvum, all these data available in literature were coincident with our spectral values. Solanum torvum has been reported for a number of potential pharmacologically active compounds like isoflavonoid sulphate and steroidal glycosides (Yahara et al. 1996; Arthan et al. 2002), chlorogenone and neochlorogenone (Carabot et al. 1991), triacontane derivatives (Mahmood et al. 1983, 1985), 22- $\beta$-O-spirostanol oligoglycosides (Iida et al. 2005) and 26- $O$ - $\beta$-glucosidase (Arthan et al. 2006). Torvoside $\mathrm{K}$ was reported as novel compound in S. torvum by Yahara et al. (1996) and Iida et al. (2005), and it is reported for anticonvulsuion activity (Challal et al. 2014). There are no reports on antifungal and antimycotoxigenic effects of torvoside $\mathrm{K}$.

In antifungal assays viz., poisoned food technique and broth microdilution method, the differences in the degree of fungal inhibition were evident between both storage and field fungal species tested, which showed that storage fungi viz., species of Aspergillus and Penicillium, were more resistant when compared to field fungi viz., species of Alternaria, Curvularia and Fusarium. Antifungal activity of test samples was recorded in term of MIC/MFC. The MFC of TK for complete inhibition of growth of the aflatoxigenic strain of A. flavus was recorded at $500 \mu \mathrm{g} \mathrm{ml}^{-1}$ in broth microdilution method, similarly in antiaflatoxigenic assay, mycelia was completely inhibited at $500 \mu \mathrm{g} \mathrm{ml}^{-1}$. The MFC of TK for complete inhibition of fumonisinogenic strain of $F$. verticillioides was $250 \mu \mathrm{g} \mathrm{ml}^{-1}$, whereas mycelia was completely inhibited at $500 \mu \mathrm{g} \mathrm{ml}^{-1}$ in antiaflatoxigenic assay. It was interesting to note that the minimum inhibitory concentrations for toxigenic strains of $A$. flavus and $F$. verticillioides were 125 and $62.5 \mu \mathrm{g} \mathrm{ml}^{-1}$, respectively, the values were almost similar to standard fungicide zinc ethylene bisthiocarbamate. The MIC values were determined against different test fungal species using broth microdilution method. This method offers better opportunity to test samples to come in close contact with fungi as both of them are homogenously distributed inside the medium as it has been earlier reported by Prakash et al. (2014). MIC values of TK were comparable to synthetic fungicide zinc ethylene bisthiocarbamate; however, copper oxychloride was found lease effective than all the samples tested. The antifungal effect of both $\mathrm{CE}$ and TE was stronger than that observed for copper oxychloride 50\%, a synthetic contact fungicide used against a wide range of plant diseases.

Antimycotoxigenic efficacy of CE and TK on inhibition of mycelial growth and production of aflatoxin B1 by A. flavus and fumonisin B1 by F. verticillioides were evaluated using in vitro and in vivo assays. During antimycotoxigenic assay in culture medium, a gradual decrease in MDW and mycotoxin production by A. flavus and F. verticillioides, was observed with increasing concentration of CE and TK. Results showed a positive correlation between the subsequent decrease in mycelial growth and mycotoxin production in vitro with increasing concentrations of TK and CE. The TK was more efficacious as mycotoxin suppressor in culture medium than viable maize as it caused complete inhibition of aflatoxin B1 secretion by $A$. flavus and fumonisin B1 by F. verticillioides at $250 \mu \mathrm{g} \mathrm{ml}^{-1}$. Both aflatoxin and fumonisin productions were completely inhibited by TK in maize at higher concentrations, at 1000 and $500 \mu \mathrm{g} \mathrm{ml}^{-1}$, respectively. The maize, which is susceptible to common fungal infestation, was selected as model for this study. Conditions studied in vivo were close to conditions that may occur during pre- and post-harvest of maize. In most of the cases, seed treatment was most effective in suppression of seed borne fungi with no effect on seedling vigour (data not shown). Maize is one of the most important crops worldwide; however, a good substrate for growth, development and activity of filamentous fungi. Maize is associated with a large number of fungal species belonging to the species of Aspergillus, Fusarium and Penicillium, that can cause spoilage and mycotoxin contaminations (Soares et al. 2013). Results of this study revealed that the TK and $\mathrm{CE}$ were found effective in inhibiting the growths of different test fungi belong to species of Aspergillus, Fusarium and Penicillium. However, Penicillium spp. was found more resistant among the fungi tested, but toxigenic strains of A. flavus and F. verticillioides were effectively inhibited in vitro and in vivo. Both aflatoxins and fumonisins are relevant in maize and maize-based foods and feeds due to their widespread occurrence and co-occurrence (Chulze 2010).

The results from the measurement of ergosterol content demonstrated that the TK caused adverse effect on plasma membrane of the toxigenic strains of A. flavus and F. verticillioides. The results revealed that the ergosterol content (at $282 \mathrm{~nm}$ ) in the plasma membrane of both $A$. flavus and F. verticillioides was completely inhib- 
ited at concentrations higher than $250 \mu \mathrm{g} \mathrm{ml}^{-1}$. Ergosterol, a sterol, is specific to fungi and is the major sterol component of the fungal cell membrane. It is also responsible for maintaining the cell function and integrity (Tian et al. 2012). Hence, ergosterol is a potential target for antifungal drug. Different classes of antifungal agents viz., polyene antibiotics, azole derivatives and allylamines/ thiocarbamates, they target ergosterol, the major sterol in the fungal plasma membrane (Georgopapadakou 1998). The primary mechanism of action by which azole antifungal drugs inhibit fungal growth is disruption of normal sterol biosynthetic pathways, leading to a reduction in ergosterol biosynthesis (Kelly et al. 1995). The depletion of ergosterol disrupts the structure of the plasma membrane, making it more vulnerable to further damage, and alters the activity of several membrane-bound enzymes, such as those associated with nutrient transport and chitin synthesis. Severe ergosterol depletion may additionally interfere with the hormone-like functions of ergosterol, affecting cell growth and proliferation (Georgopapadakou 1998). Keeping this point in view, the antifungal mode of action of TK was assessed by measuring the total intracellular ergosterol contents in fungal cells with increasing concentrations of TK. Our observations revealed that there was an adverse effect on ergosterol content, therefore, it confirms the considerable impairment of the biosynthesis of ergosterol in plasma membrane of A. flavus and F. verticillioides. However, further experiments are required to understand the exact mode of action of the TK on plasma membrane and its correlation with the inhibition of aflatoxin biosynthesis.

Plant products are expected to be more advantageous over synthetic fungicides because of their biodegradable nature, and the abundance of raw materials because of luxuriant growth of the plants and their renewable nature makes use of plant products economical for practical application (Marin et al. 2011). The identification of antifungal compounds from plants is one of the promising and alternative strategies for preventing fungal-deterioration and mycotoxin contaminations. Results presented in this study confirmed that the TK isolated from S. torvum leaves was effective for the inhibition of growth of important mycotoxigenic fungi commonly associated with deterioration of food and feedstuffs. TK inhibited the growth of toxigenic strains of A. flavus and F. verticillioides, and their toxin productions at even high water activity levels, and was also found effective against a wide range of field and storage fungi. Solanum torvum, being the plant used in traditional medicine, possesses broad spectrum antifungal activity against important field and storage moulds that would probably be a good source of antifungal agents for prevention of fungal-deterioration and mycotoxin contaminations. This study indicates that the compound TK has considerable antifungal and antimycotoxigenic activity, deserving further toxicological investigations for future application.

\section{Acknowledgements}

Authors are grateful to the Department of Science and Technology, Government of India, New Delhi (India) for the financial support. The authors thank the Indian Institute of Science, Bengaluru (India) for providing spectral analyses and interpretation.

\section{Conflict of Interest}

No conflict of interest declared.

\section{References}

Al-Reza, S.M., Rahman, A., Ahmed, Y. and Kang, S.C. (2010) Inhibition of plant pathogens in vitro and in vivo with essential oil and organic extracts of Cestrum nocturnum $\mathrm{L}$. Pestic Biochem Physiol 96, 86-92.

Arthan, D., Svasti, J., Kittakoop, P., Pittayakhachonwut, D., Tanticharoen, M. and Thebtaranonth, Y. (2002) Antiviral isoflavonoid sulfate and steroidal glycosides from the fruits of Solanum torvum. Phytochemistry 59, 459-463.

Arthan, D., Kittakoop, P., Esen, A. and Svasti, J. (2006) Furastanol-26-O- $\beta$-glucosidase from the leaves of Solanum torvum. Phytochemistry 67, 27-33.

Bailly, J.D., Querin, A., Tardieu, D. and Guerre, P. (2005) Production and purification of fumonisins from a highly toxigenic Fusarium verticillioides strain. Rev Med Vet (Toulouse) 156, 547-554.

Balachandran, C., Duraipandiyan, V., Al-Dhabi, N.A., Balakrishna, K., Kalia, N.P., Rajput, V.S., Khan, I.A. and Ignacimuthu, S. (2012) Antimicrobial and antimycobacterial activities of methyl caffeate isolated from Solanum torvum Swartz. fruit. Indian J Microbiol 52, 676-681.

Bari, M.A., Islam, W., Khan, A.R. and Mandal, A. (2010) Antibacterial and antifungal activity of Solanum torvum (Solanaceae). Int J Agric Biol 12, 386-390.

Carabot, C.A., Blunden, G. and Patel, V.A. (1991) Chlorogenone and neochlorogenone from the unripe fruits of Solanum torvum. Phytochemistry 30, 1339-1341.

Chah, K.F., Muko, K.N. Oboegbulem, S.I. (2000) Antimicrobial activity of methanolic extract of Solanum torvum fruit. Fitoterapia 71, 187-189.

Challal, S., Buenafe, O.E.M., Queiroz, E.F., Maljevic, S., Marcourt, L., Bock, M., Kloeti, W., Dayrit, F.M. et al. (2014) Zebrafish bioassay-guided microfractionation identifies anticonvulsant steroid glycosides from the philippine medicinal plant Solanum torvum. ACS Chem Neurosci 5, 993-1004. 
Chulze, S.N. (2010) Strategies to reduce mycotoxin levels in maize during storage: a review. Food Addit Contam 27, 651-657.

Cuervo, A.C., Blunden, G. and Patel, A.V. (1991) Chlorogenone and neochlorogenic from unripe fruits of Solanum torvum. Phytochemistry 30, 1339-1341.

Ficoseco, M.E.A., Vattuone, M.A., Audenaert, K., Catalan, C.A.N. and Sampietro, D.A. (2014) Antifungal and antimycotoxigenic metabolites in Anacardiaceae species from northwest Argentina: isolation, identification and potential for control of Fusarium species. J Appl Microbiol 116, 1262-1273.

Garcia, D., Ramos, A.J., Sanchis, V. and Marin, S. (2012) Effect of Equisetum arvense and Stevia rebaudiana extracts on growth and mycotoxin production by Aspergillus flavus and Fusarium verticillioides in maize seeds as affected by water activity. Int J Food Microbiol 153, 21-27.

Georgopapadakou, N.H. (1998) Antifungals: mechanism of action and resistance, established and novel drugs. Curr Opin Microbiol 1, 547-557.

Hajji, M., Jarraya, R., Lassoued, I., Masmoudi, O., Damak, M. and Nasri, M. (2010) GC/MS and LC/MS analysis, and antioxidant and antimicrobial activities of various solvent extracts from Mirabilis Jalapa tubers. Process Biochem 45, 1486-1493.

Harborne, J.B. (1998) Phytochemical Methods: A Guide to Modern Techniques of Plant Analysis, 3rd edn. London: Chapman \& Hall.

Iida, Y., Yanai, Y., Ono, M., Ikeda, T. and Nohara, T. (2005) Three unusual 22- $\beta$-O-23-hydroxy-( $5 \alpha)$-spirostanol glycosides from the fruits of Solanum torvum. Chem Pharm Bull 53, 1122-1125.

Israf, D.A., Lajis, N.H., Somchit, M.N. and Sulaiman, M.R. (2004) Enhancement of ovalbumin specific IgA responses via oral boosting with antigen co-administered with an aqueous Solanum torvum extract. Life Sci 75, 397-406.

Kelly, S.L., Lamb, D.C., Corran, A.J., Baldwin, B.C. and Kelly, D.E. (1995) Mode of action and resistance to azole antifungals associated with the formation of 14 alphamethylergosta-8,24(28)-dien-3 beta, 6 alpha-diol. Biochem Biophys Res Commun 207, 910-915.

Khaledi, N., Taheri, P. and Tarighi, S. (2014) Antifungal activity of various essential oils against Rhizoctonia solani and Macrophomina phaseolina as major bean pathogens. J Appl Microbiol 118, 704-717.

Kumar, A., Shukla, R., Singh, P., Prasad, C.S. and Dubey, N.K. (2008) Assessment of Thymus vulgaris L. essential oil as a safe botanical preservative against post harvest fungal infestation of food commodities. Innov Food Sci Emerg Technol 9, 575-580.

Lalitha, V., Raveesha, K.A. and Kiran, B. (2010) Antimicrobial activity of Solanum torvum Swart. against important seed borne pathogens of paddy. Iranica J Energy Environ 1, 160-164.
Loganayaki, N., Siddhuraju, P. and Manian, S. (2010) Antioxidant activity of two traditional Indian vegetables: Solanum nigrum L. and Solanum torvum L. Food Sci Biotechnol 19, 121-127.

Lutfullah, G. and Hussain, A. (2012) Studies on contamination level of aflatoxins in some cereals and beans of Pakistan. Food Control 23, 32-36.

Mahmood, U., Shukla, Y.N. and Thakur, R.S. (1983) Nonalkaloidal constituents from Solanum torvum leaves. Phytochemistry 22, 167-170.

Mahmood, U., Agrawal, P.K. and Thakur, R.S. (1985) Torvonin-A, a spirostane saponin from Solanum torvum leaves. Phytochemistry 24, 2456-2457.

Marin, S., Sanchis, V. and Ramos, A.J. (2011) Plant products in the control of mycotoxins and mycotoxigenic fungi on food commodities. In Natural Products in Plant Pest Management ed. Dubey, N.K., pp 21-41. Oxfordshire, UK: CAB International.

Mohana, D.C., Raveesha, K.A. and Rai, K.M.L. (2008) Herbal remedies for the management of seed-borne fungal pathogens by an edible plant Decalepis hamiltonii (Wight \& Arn). Arch Phytopathol Plant Prot 41, 38-49.

NCCLS. (2002) Performance Standards for Antimicrobial Susceptibility Testing. Twelfth Informational Supplement, NCCLS document M100-S12. Wayne, PA: NCCLS.

Ndebia, E.J., Kamgang, R. and Nkeh-Chungaganpe, B.N. (2007) Analgesic and anti-inflammatory properties of aqueous extract from leaves of Solanum torvum (Solanaceae). Afr J Tradit Complement Altern Med 42, 240-244.

Nguefack, J., Dongmo, J.B.L., Dakole, C.D., Leth, V., Vismer, H.F., Torp, J., Guemdjom, E.F.N., Mbeffo, M. et al. (2009) Food preservative potential of essential oils and fractions from Cymbopogon citratus, Ocimum gratissimum and Thymus vulgaris against mycotoxigenic fungi. Int $J$ Food Microbiol 131, 151-156.

Nguelefack, T.B., Feumebo, C.B., Ateufack, G., Watcho, P., Tatsimo, S., Atsamo, A.D., Tane, P. and Kamanyi, A. (2008) Anti-ulcerogenic properties of the aqueous and methanol extracts from the leaves of Solanum torvum Swartz (Solanaceae) in rats. J Ethnopharmacol 119, 135140.

Placinta, C.M., D’Mello, J.P.F. and Macdonald, A.M.C. (1999) A review of worldwide contamination of cereal grains and animal feed with Fusarium mycotoxins. Anim Feed Sci Technol 78, 21-37.

Prakash, B., Mishra, P.K., Kedia, A. and Dubey, N.K. (2014) Antifungal, antiaflatoxin and antioxidant potential of chemically characterized Boswellia carterii Birdw essential oil and its in vivo practical applicability in preservation of Piper nigrum L. fruits. LWT - Food Sci Technol 56, 240-247.

Probst, C. and Cotty, P.J. (2012) Relationships between in vivo and in vitro aflatoxin production: reliable prediction of fungal ability to contaminate maize with aflatoxins. Fungal Biol 116, 503-510. 
Ramamurthy, C.H., Kumar, M.S., Suyavaran, V.S.A., Mareeswaran, R. and Thirunavukkarasu, C. (2012) Evaluation of antioxidant, radical scavenging activity and polyphenolics profile in Solanum torvum L. fruits. J Food Sci 77, 907-913.

Reddy, K.R.N., Salleh, B., Saad, B., Abbas, H.K., Abel, C.A. and Shier, W.T. (2010) An overview of mycotoxin contamination in foods and its implications for human health. Toxin Rev 29, 3-26.

Rosas-Taraco, A., Sanchez, E., Garcia, S., Heredia, N. and Bhatnagar, D. (2011) Extracts of Agave americana inhibit aflatoxin production in Aspergillus parasiticus. World Mycotoxin J 4, 37-42.

Shukla, R., Singh, P., Prakash, B. and Dubey, N.K. (2012a) Antifungal, aflatoxin inhibition and antioxidant activity of Callistemon lanceolatus (Sm.) Sweet essential oil and its major component 1,8-cineole against fungal isolates from chickpea seeds. Food Control 25, 27-33.

Shukla, R., Singh, P., Prakash, B., Anuradha, and Dubey, N.K. (2012b) Antifungal, aflatoxin inhibitory and free radicalscavenging activities of some medicinal plants extracts. $J$ Food Qual 35, 182-189.

Sivapriya, M. and Srinivas, L. (2007) Isolation and purification of a novel antioxidant protein from the water extract of sundakai (Solanum torvum) seeds. Food Chem 104, 510-517.
Soares, C., Calado, T. and Venancio, A. (2013) Mycotoxin production by Aspergillus niger aggregate strains isolated from harvested maize in three Portuguese regions. Rev Iberoam Micol 30, 9-13.

Thippeswamy, S., Mohana, D.C., Abhishek, R.U. and Manjunath, K. (2013) Efficacy of bioactive compounds isolated from Albizia amara and Albizia saman as source of antifungal and antiaflatoxigenic agents. $J$ Verbrauch Lebensm 8, 297-305.

Thippeswamy, S., Mohana, D.C., Abhishek, R.U. and Manjunath, K. (2014) Inhibitory effect of alkaloids of Albizia amara and Albizia saman on growth and fumonisin $\mathrm{B}_{1}$ production by Fusarium verticillioides. Int Food Res J 21, 947-952.

Tian, J., Huang, B., Luo, X., Zeng, H., Ban, X., He, J. and Wang, Y. (2012) The control of Aspergillus flavus with Cinnamomum jensenianum Hand.-Mazz essential oil and its potential use as a food preservative. Food Chem 130, 520-527.

Tripathi, P., Dubey, N.K., Banerji, R. and Chansouria, J.P.N. (2004) Evaluation of some essential oils as botanical fungitoxicants in management of post-harvest rotting of citrus fruits. World J Microbiol Biotechnol 20, 317-321.

Yahara, S., Yamashita, T., Nozawa, N. and Nohara, T. (1996) Steroidal glycosides from Solanum torvum. Phytochemistry 43, 1069-1074. 